\title{
Librarians Aren't Born with Information Superpowers: Leveling the Playing Field for Incoming Library Science Graduate Students
}

\author{
Annette Lamb, Ph.D. \\ Senior Lecturer \\ Library and Information Science \\ Indiana University - Purdue University Indianapolis \\ anlamb@iupui.edu
}

\begin{abstract}
Students enter the library science graduate program with a wide range of information and technology skills. Today's graduate courses require students to be able to build web-based pathfinders, use social media, and search databases. This article examines the design and development of an introductory course for incoming library science graduate students that personalizes instruction and ensures that each student is ready for the rigors of graduate school. Taken during the first semester of the program, this introductory course teaches information and technology skills and concepts that are core to library science. The author explores the process of creating a computer-based course that addresses the diverse needs of this student population.

Using a systematic approach to instructional design and development, the author outlines the steps in designing, developing, implementing, and evaluating an online, self-paced graduate course. Based on the Dick and Carey model, the process included identifying the instructional goals, conducting an instructional analysis, analyzing learners and contexts, writing performance objectives, developing assessment instruments, developing instructional strategies, developing and selecting instructional materials, designing and conducting formative evaluation of instruction, revising instruction, and designing and conducting summative evaluation. This process produced effective, efficient, and appealing instructional materials.
\end{abstract}

\section{Introduction}

Although library users may assume that librarians are born with innate "Boolean abilities," students entering the library science graduate program at Indiana University at Indianapolis don't arrive with information superpowers. Instead, they come to the program with a wide range of information literacy skills. While some entering students lack even basic search and citation skills, others have advanced knowledge, including the ability to generate metadata and build digital collections. Many students come to the program with good grades and practical library experiences, but few learners enter with the breadth of information and technology skills needed to be successful in today's library science graduate program. 


\section{The Need}

Since the graduate program's inception, the Department of Library and Information Science at Indiana University has offered a beginning course intended to ensure that incoming students have the entry-level knowledge and skills necessary to excel in the graduate program. This course is offered during the first semester of the students' studies, and is required for all students in the program. This introductory course was originally offered face-to-face. Over time, it shifted to a blended model and ultimately was offered entirely online. The course was juggled among full-time and adjunct faculty, making the content inconsistent and the results less than effective. From building blogs to creating electronic pathfinders, information and technology projects were woven throughout the graduate program's array of course offerings. To be successful, students needed to be information and technology fluent. As the library science graduate program moved entirely online, it became imperative that students had the entry skills necessary to work independently and at a distance. However, it was also important that students not waste valuable time receiving instruction in areas where they already had the necessary skills.

In Fall 2013, the department was updating its strategic plan. Curriculum alignment was identified as an important objective. Creating a strategy for aligning the information and technology objectives within the curriculum was identified as a strategic plan action item. This department initiative, combined with the need to address concerns about the introductory course, provided an impetus for this instructional development project.

In order to enhance the pedagogical effectiveness of the course and ensure a consistent, high-quality outcome, the course was totally redesigned.

\section{Information \& Technology Literacy Instruction}

A number of recent studies (Daugman, McCall, \& McMahan, 2012; Gunn \& Miree, 2012; Weiner, Pelaez, Chang, \& Weiner, 2012) have focused on the development of information literacy courses for specific disciplines such as business, health care, and humanities. According to Kumar, Ochoa and Edwards (2012), support for the acquisition and updating of information literacy skills is important in online learning situations. Specifically, online students need skills in the use of digital resources to support their learning needs.

Lacy and Chen (2013) note the importance of establishing learning outcomes to demonstrate the effectiveness of information literacy instruction. In other words, evidence must be provided to confirm learning. In their study, instructors collected assessment data to determine if students possessed the required skills. This learnercentred approach involves identifying exactly what learners should be able to do or talk about at the end of the instruction. According to Kaplowitz (2012), emphasis should be placed on whether students can demonstrate their knowledge and skills rather than on the act of teaching. 
Increasingly, a systematic approach is being applied to the design and development of information literacy skills instruction (Booth, 2011; Kumar, Ochoa, \& Edwards, 2012). A systematic approach in instruction involves careful planning and alignment at each stage of development. For instance, assessment items are based on performance objectives. In turn, objectives are based on goals that are carefully designed based on the needs of learners.

\section{Instructional Design Model}

Having taught graduate education courses in instructional design and development, and having developed 22 online graduate courses since 2002, the researcher was aware of the importance of applying a systematic approach to the design of instruction. After considering a number of approaches (e.g., ADDIE, ARCS, ASSURE, Backward Design, Dick and Carey, Kemp Design Model), the researcher selected the Dick and Carey (2009) model because it considers the recursive relationship of learner characteristics, performance objectives, criterion-referenced assessment, and instructional materials in order to bring about desired learning outcomes. As an empirical and replicable process, the Dick and Carey model ensures that all students reach mastery and are ready for the rigor of the graduate program in library science.

This instructional design and development project followed the Dick and Carey (2009) model's steps:

1. Identify instructional goal(s)

2. Conduct instructional analysis

3. Analyze learners and contexts

4. Write performance objectives

5. Develop assessment instruments

6. Develop instructional strategy

7. Develop and select instructional materials

8. Design and conduct formative evaluation of instruction

9. Revise instruction

10. Design and conduct summative evaluation

\section{Step 1: Identify Instructional Goal(s)}

The first step in identifying instructional goals was specifying the performance problem. 
In a Fall 2013 survey of alumni, graduates identified technology as an important skill. Also in Fall 2013, faculty expressed concerns about the inconsistency of student information literacy knowledge and skills among graduate students entering the library science graduate courses. While some students demonstrated the necessary entry skills after completing the required introductory course, others did not.

To address this problem, a needs assessment was conducted to determine what knowledge and skills students needed to be successful in the library science graduate program.

Kaufman and English (1979) suggests that researchers examine the current results, describe the desired results, and identify the differences to determine the needs. In this case, the researcher conducted a multi-pronged needs assessment to identify gaps between the current course conditions and the desired conditions, and aimed to determine what level of computer and information skill mastery was necessary for incoming students to be successful in subsequent courses.

The needs assessment activities focused on the course learning objectives, which describe the knowledge and skills that learners should be able to exhibit following instruction.

The first phase of needs assessment involved comparing the original course learning objectives with courses offered at other similar ALA-accredited library science programs. The syllabi of fourteen courses were identified online. A combined list of knowledge and skills was produced. The most commonly-found areas included basic technology use (e.g., word processing), digital communication tools (e.g., using email), and information retrieval (e.g., using subscription databases).

During the second phase, the original course learning objectives were compared to national and international technology and information literacy standards. Farmer (2011) notes that information literacy, technology literacy, and other supporting literacies are all important to librarians and information professionals. Standards from the following organizations were examined: the Association of College and Research Libraries (ALA, 2000), the International Society for Technology in Education (ISTE, 2015), the American Association for School Librarians (AASL, 2007), and the Chartered Institute of Library and Information Professionals (CILIP, 2014). During this time, the ACRL Standards Committee was in the process of revising their information literacy competencies. The discussions of the ACRL Board (2015) were also considered when developing the course learning objectives. Tyron, Frigo, and O'Kelly (2010) suggest adapting information literacy standards to address the needs of specific disciplines.

A number of researchers (Bester \& Scholtz, 2012; Charles, 2015; Hale, 2008; Uchiyama \& Radin, 2009) have found that curriculum mapping in the area of information literacy is an effective way to identify information skills and how they are addressed in the curriculum. In the third phase, the original objectives were compared with the objectives of other courses in the graduate program. Each course syllabus in the graduate 
program was examined to identify where information and technology knowledge and skills are introduced, reinforced, and mastered.

- Introduced (I). The student defines the concept, provides examples, and uses this knowledge or skill with support.

- $\quad$ Reinforced (R). The student analyzes additional examples and practices use of the knowledge or skill in a meaningful way.

- Mastered (M). The student applies the knowledge or skill to a new situation independently.

For instance, the learning outcome "define and provide examples of open access" was tagged with the following levels in each of the following courses: s401-I; s501-R; s506R; s516-M; s533-M; s554-R; s621-R; s652-RM; s653-M.

The skills developed in the introductory course should seamlessly carry over to technology-intensive courses such as online searching, digital libraries, library systems, electronic resources management, and web architecture, as well as the courses that weave information and technology throughout course content and assignments. For example, the concept of controlled vocabulary was identified as an entry skill for the graduate course in online searching. As such, this skill was included in the introductory course.

In the next phase, faculty were asked the following questions:

- What basic library and information science skills do you expect from students entering your courses?

- What technology skills do you expect from students entering your courses?

- Are there technical skills (e.g., hardware, software, social technology, management) that you think are essential?

- Is there terminology (e.g., controlled vocabulary, OPAC) or LIS professional entry skills (e.g., basic search strategies, citation skills) that you expect students to know before entering your course?

- When students exit your courses, what information and technology skills have been introduced, reinforced, or mastered (e.g., upload book trailers to YouTube or build an RSS feed in XML)?

Faculty were also asked to examine the objectives to see if they agreed with the entry skills related to technology and information, along with the points at which skills are introduced, reinforced, and mastered.

Instructors held assumptions about what prerequisite skills students would possess when they entered their courses. However, these notions were not always stated 
explicitly in the course syllabi. For instance, a faculty member might assume that students knew how to create a bibliography applying APA style or use an online tool such as Weebly to create a webpage. Instructors were asked to look at the newlycompiled list of learning outcomes from the earlier phases and add other knowledge and skills.

The final phase involved categorizing the knowledge and skills. Four categories were established: 1) basic technology and information retrieval skills, 2) collection development and productivity tools, 3) social media and participatory technology, and 4) advanced technology, ethics, and professionalism. These four categories showed that the desired outcomes reached beyond traditional information literacy categories to include basic knowledge of library science and advanced technology skills.

The researcher concluded that the performance problem could be solved by developing effective, efficient, and appealing instruction that stressed the mastery of knowledge and skills in these four categories. The resulting instructional goal stated that graduate students completing the course would be able to apply information, library science, and technology skills to address problems in school, academic, public, and/or special library settings.

\section{Step 2: Conduct Instructional Analysis}

During the needs assessment process, four categories of outcomes were identified. However, no attempt was made to identify subordinate skills. In other words, an instructional analysis was needed to ensure that nothing was missed. Dick, Carey, and Carey (2009) asked the question, "What exactly would learners be doing if they were accomplishing the goal successfully?" (p. 39).

A combination chart including both hierarchical and procedural elements was constructed for clusters of learning outcomes. Gagné, Wager, Golas, and Keller (2004) note that to perform problem-solving skills, learners must be able to apply skills in a particular order. Some skills may function as prerequisites to others. In other words, before a library student can conduct a subject analysis, he or she must be able to define the terms "subject," "subject heading," and "controlled vocabulary." Although these small steps may seem insignificant, they can have a tremendous impact on learning. For instance, faculty were jumping into teaching advanced concepts related to subject analysis before realizing that some students didn't possess the required entry skills.

Faculty became important subject matter experts during the instructional analysis component of development. For instance, a faculty member teaching a course in research and evaluation was concerned that students in her course were unable to successfully create electronic spreadsheets in her course. The skill of "creating electronic spreadsheets" was broken down into specific knowledge and skills. Ultimately, the performance problem was identified as the ability to create specific formulas when building electronic spreadsheets. 
After charting the relationships among the skills and sub-skills, entry skills were identified. A line needed to be drawn between those skills that students would possess upon entry and those skills taught in the introductory course. While we assumed that students could identify and use a keyboard, could they also identify and use a flatbed scanner? Students could use a word processor, but could they create an electronic spreadsheet? This was difficult to determine because of the broad backgrounds of incoming library science students. Many university-produced instructional materials were already available on basic hardware and software skills as well as entry-level information literacy topics. The researcher decided to provide supplemental resources for those students who might need help with entry skills.

\section{Step 3: Analyze Learners and Contexts}

In order to develop high-quality instruction, the needs and interests of the audience must be considered (Farmer, 2011). Information about the students was available in their graduate school applications. In addition, students posted a short biographical sketch in the discussion area of the online introductory course to introduce themselves. These introductions provided insights into the typical entering student. Student biographical sketches from Summer 2013 and Fall 2013 were examined.

The results indicated that a majority of students entering the program were females of varying ages. These students came from many different academic backgrounds. While some students had no experience within a library, many had experiences ranging from volunteer work to professional library positions. Entering learners held interests in school, public, academic, and special library areas. Almost all students were interested in professional positions related to librarianship.

The researcher concluded that introducing information and technology knowledge and skills as they relate to the library profession would better prepare students for more advanced courses, and would give them a sense of some of the specializations that might be of interest. Using examples associated with a student's professional goals may also increase academic motivation (Keller, 2010).

\section{Step 4: Write Performance Objectives}

The learning outcomes identified during the needs assessment and instructional goal identification phases were further refined during the instructional analysis phase. In Step 4 , these learning outcomes were re-written as performance objectives that included conditions, behaviour, and criteria (Mager, 1997). This level of specification is foundational for creating closely-aligned assessments and instructional activities. A total of 410 objectives were identified. Here is an example:

- Course Learning Outcome: Identify errors in bibliographic citations.

- Performance Objective: Given a bibliographic citation containing 3 errors, the student will be able to identify and correct all three errors. 


\section{Step 5: Develop Assessment Instruments}

Assessments allow the instructor to determine to what degree students are mastering the performance objectives (Dick, Carey, \& Carey, 2009; Ivanitskaya, DuFord, Craig, \& Casey, 2008; Lowe, Booth, Tagge, \& Stone, 2014; Radcliff, Jensen, Salem, Burhanna, \& Gedeon, 2007). In this case, criterion-referenced assessments are learner-centered and linked directly to the performance objectives.

For each performance objective, either test items or practical demonstration items were generated. For instance, a test item was used to determine whether students could differentiate between open source and proprietary software. However, a practical demonstration item meant the student displayed proficiency in converting a Microsoft Word document to a PDF file. The test items are designed to ensure that all students possessed the basic knowledge, and the practical demonstration items determine technical skills with products generated by students.

Three types of assessment instruments were developed. First, pre-test items were created to match performance objectives. Second, post-tests were generated for each of the four sections of the course. Third, proficiency project items (i.e. tasks that demonstrated application of the expected skill) were generated for those objectives associated with practical skills.

Pre-test items were generated to match each performance objective. The items included multiple-choice, true/false, and matching questions. Below is an example:

- Performance Objective: Given a real-world library situation, identify examples of when a Virtual Private Network (VPN) might be used without error.

- Pre-test Item: You're the new corporate librarian at a tech firm. Which of the following is NOT a reason for using a VPN?

o VPN allows users to run Windows software on a Mac.*

o VPN allows a secure connection to work from home.

o VPN allows access to some library databases otherwise restricted to onsite use.

o VPN allows individuals to use wi-fi hotspots securely.

Post-test items were aligned with performance objectives in each of the four major course categories. Four test banks were generated with multiple-choice, true/false, and matching items. A subset of the items was used to create post-tests in each of the four areas. Below is an example:

- Performance Objective: The student will differentiate between a mOPAC and an OPAC without error. 
- Pre-test Item: You're volunteering at a library's information desk. A library user asks you to describe the difference between the mOPAC and the OPAC. What do you say?

o The mOPAC simply provides a mobile-friendly interface for accessing the OPAC.*

o The mOPAC accesses a "lite" version of the OPAC only including materials that can be accessed through mobile devices.

o The mOPAC contains additional materials such as mobile apps and mobile websites not available through the regular OPAC.

o The mOPAC is a propriety app used to access WorldCat through a mobile device.

In addition to the post-tests, four proficiency project guidelines were created. Proficiency project items were aligned to performance objectives related to practical skills. Below is an example:

- Performance Objective: Given a URL, the student will generate a shortened URL using a popular URL shortener such as Google URL Shortener.

- Proficiency Project Item: Provide a shortened URL for a webpage within the website you evaluated using one of the popular URL shorteners.

\section{Step 6: Develop Instructional Strategy}

Prior to selecting an instructional strategy, the researcher considered the instructional goal, learner characteristics, performance objectives, and assessments.

Instructional strategies assist learners in meeting the stated objectives. In the past, the introductory course included lecture materials and readings to present information and assignments that required students to answer questions and submit documents.

Options for the delivery of instruction were narrowed based on specific programmatic needs. Live, personalized, time-intensive instruction was not feasible due to large class sections. Because the introductory course was online, the instructional materials needed to be available through a web-based system. Mastery of each performance objective was important to the success of the course. As such, any instructional strategy needed to ensure that students were acquiring skills, not simply watching lectures or reading articles. The learning system needed to take into consideration the wide range of entry skills and the fact that some students entered with a large skill set. Based on the delivery requirements, a self-paced, web-based approach was selected.

The next step in developing the instructional strategy was to consider the sequencing and clustering of course content. The performance objectives were organized into 46 clusters within the four categories. These clusters were sequenced based on the 
relationships among the skills and sub-skills. In other words, prior to learning about citation management software, students needed to define and create citations.

A number of researchers (Dick, Carey, \& Carey, 2009; Farmer, 2011; Gagné, 1985; Merrill, 2013; Myers \& Lamb, 1990) have identified ways to organize instructional experiences. Instructional activities include motivating learners, informing them of the expectations, presenting new information, providing space for practice and feedback, and extending the experience. The researcher settled on the following major areas (Myers \& Lamb, 1990):

- Pre-instructional Activities: Gain the attention of learners, inform them of the learning outcomes, and review prior knowledge.

- Presentation of Information: Describe the content in small chunks and provide examples and non-examples using a variety of material types (e.g., text, images, audio, video, animation).

- Student Participation and Embedded Testing: Present opportunities to interact after each new chunk of information, provide meaningful feedback on student performance, and embed test items to check student learning.

- Follow-through Activities: Summarize important points, review examples, and highlight applications of skills to new situations.

The example below shows excerpts from a lesson focusing on social networks and libraries:

- Pre-instructional Activities:

- Do you share family photos on Facebook or participate in online book discussions on GoodReads? If so, you're using a social network... As you work your way through the tutorial, pay close attention to those areas new to you. After completing the tutorial, you'll be able to define the term social network...

- Presentation of Information:

o Social networks are virtual spaces where people of all ages can make contacts, share information and ideas, and build a sense of community...

- Student Participation and Embedded Testing:

o Social networks normally include individual profiles. Is this statement true or false?...

- Follow-through Activities: 
o Many social networks can be adapted for use by libraries. LibraryThing is an example...

To address the need for online instruction, the researcher concluded that a tutorial approach would be the most effective way to package the instructional strategies. According to Myers and Lamb (1990), "tutorials are self-instructional computer programs intended to teach your students new skills and knowledge without assistance. Most tutorials would involve information presentation, interaction with the learner, and feedback followed by guided practice and testing" (p. 3). As a result, 46 instructional tutorials were designed (See Appendix for the full list of tutorials).

\section{Step 7: Develop and Select Instructional Materials}

Because no existing instructional materials met the needs of the project, all the learning resources were developed in-house.

The first step was to identify software for development and management of instruction. The pros and cons of a number of different options, including subscription-based services, PowerPoint-driven tutorials, and others, were considered. The options were narrowed to three content management systems supported by the university: the outgoing university service called [Institution Software Name] based on Sakai, the incoming university service known as Canvas, and the ongoing university service using Adobe Captivate and Adobe Connect.

Because the transition from [Institution Software Name] to Canvas was just beginning, Adobe products were selected since they were known to be reliable and well-supported by the university. Adobe Captivate provided specific tools necessary for creating both the tests and the tutorials. By creating a template, consistency could be ensured among the tests and tutorials. The Adobe Captivate software provided multimedia tools that contributed to the efficiency, effectiveness, and appeal of the instruction. Multimedia features included embedded video, embedded websites, screen casting, audio narration, screen captures, and many other visual elements. The basic scoring options in Captivate could be connected to Adobe Connect.

As the first instructional developer on campus to connect Adobe Captivate tests and tutorials with the Adobe Connect management system, the researcher faced certain technical challenges. For example, one obstacle was gaining the level of administrative access to the Adobe Connect system necessary to upload files, assign student roles, and generate reports.

Once the software was selected, two prototype pre-tests and tutorials were created. These were uploaded to Adobe Connect. A one-on-one formative evaluation was conducted with a test subject to determine whether the system was operating properly. After entering their username and password, the test subject was presented with a list of pre-tests and matching tutorials. Only the first pre-test was "available" to the student. The first pre-test was used to determine whether the student possessed knowledge and skills related to a small cluster of objectives. If the learner did not pass the pre-test, he 
or she would be presented with a self-instructional tutorial related to this cluster of objectives. The second pre-test would not be accessible to the student until the first tutorial was successfully completed. If the student passed the first pre-test, the student would not be presented with the tutorial. Instead, the student would be presented with the opportunity to take the second pre-test. The system worked well for the test subject, so the rest of the pre-tests and tutorials were created and uploaded.

In order to address the needs of diverse learners, the tutorials included both text and at least one image on each informational screen. In many cases, multimedia features such as screen captures and videos were embedded. Students were required to make a choice in order to move from screen to screen within the tutorial. Many of these interactions involved embedded test items with corrective feedback.

Once the computer-based materials were complete, the administrative elements of the course were developed following best practices for online teaching. In other words, although the course is essentially self-paced, the instructor still plays an essential role in motivating students, answering their questions, and keeping them on track. To ensure consistency among faculty teaching the course, teaching guidelines, suggested feedback, and course announcements were developed.

\section{Step 8}

Prior to fully implementing the course, a formative evaluation was conducted. This involved two phases.

First, department faculty were invited to explore the course materials and provide feedback. Faculty were asked to look for problems with the use of tutorials as well as errors in the content. In addition to examining the assessments and tutorials, they were also asked to examine the course syllabus, guide, and schedule.

Faculty identified a few typos and other small errors. Most of the comments focused on connections with other courses and jumpstarted discussions about the need for program-wide curriculum development and alignment.

Second, a small class in Spring 2014 served as a field trial for the course. The results of the pre-tests, tutorials, and exams were carefully examined to identify common problems. The Adobe Connect system provided comprehensive records related to student activities, which helped to automate data collection. The item analysis and time record features were particularly valuable. For instance, the system provided information about the amount of time spent on tutorials, showing that many students quickly completed the basic technology tutorials but spent more time on librarianshipspecific topics and more advanced technology topics. The item analysis feature was used to identify a few unnecessary and ineffective questions.

After the course was completed, students provided their regular course evaluations. However, they were also asked for their candid comments and suggestions. The primary feedback received was used to update the course materials. 


\section{Step 9: Revise Instruction}

According to the Dick and Carey model (Dick, Carey, \& Carey, 2009), the next phase in the instructional design and development process was the revision of instruction.

Based on suggestions from faculty, changes were made in the course materials. For instance, one faculty member suggested shifting the course schedule by a couple of weeks to ensure that students who took the course s401 (Computer-Based Information Tools) concurrently with s501 (Information Sources and Services) would have skills in social technology and web development earlier in the semester.

Based on suggestions from students, many typos and small errors in content were corrected. In addition, some of the management features of Adobe Connect were modified. For instance, the system was modified to allow students to review pre-test items after completing the tutorial. Some students who were not required to complete particular tutorials because of their pre-test scores wanted to have access to the tutorial anyway. This access was provided for all students. Finally, some students indicated that they would like to have access to the text of the tutorials and the links provided in the tutorials for review prior to taking the exams. Webpages were created to match the 46 tutorials.

Based on reports generated by Adobe Connect, some test items were replaced or modified.

\section{Step 10: Design and Conduct Summative Evaluation}

A summative evaluation was conducted to determine whether the instruction was effective with learners. After four semesters, a final evaluation was completed to ensure that the course was meeting the instructional goal. Course records and reports generated by the Adobe Connect management system were examined. In addition, course evaluations were collected and analyzed. Based on course records, 131 students enrolled in the course over the four-semester period. Of these, 121 students passed the course, four students did not complete the course, two students failed the course, and four students withdrew from the course. Each of the ten students who did not pass the course indicated that the course materials themselves did not impact their ability to pass the course.

Course evaluations from four semesters provided student insights regarding the effectiveness, efficiency, and appeal of the course. The course evaluations included Likert-type scale questions (1-low; 4-high) and open-ended questions. The overall average for the course was 3.69 on a 4-point scale compared to the school average of 3.54. Students thought the course was a useful element of their graduate program, and the course received an average of 3.71 on a 4-point scale. One student stated, "I understand why this course is a pre-requisite for the LIS Master's program! This course did an excellent job covering A LOT of technological and foundational material that will absolutely be used moving forward in coursework and my professional career. I liked being introduced to a variety of online technologies that I was not familiar with and 
learning more about each." Students also found the course goals and objectives to be clear (3.80) and the course materials helpful (3.69) and easy to follow (3.75). A few students noted that the course coverage and organization was effective for the intended audience. For example, one student noted that "it hit on all the major technology and computer support that librarians will encounter in their line of work. Each project we did used the skills we learned in the tutorials."

Students felt that the course was well-organized. One student stated, "the course goals and assignments were very easy to understand and feedback on assignments was quick and helpful. The online tutorials were interesting and helpful." Another student stated, "I like how she had the course laid out, so that it could be digested piece-bypiece. I was a little overwhelmed when I first saw the course load, but the way the instructor planned it, we could handle all the information."

Students also found the course instructions to be sufficient (3.69). One student stated, "I really appreciated the transparent nature of the course and the fact that I always knew what I needed to accomplish. I also really enjoyed being able to work ahead." Many students expressed their appreciation for the self-paced approach, e.g., "I enjoyed... the way the course was set up to be completed at your own pace. It really helped me to be able to get ahead in the course then when things got busier for me I wasn't tied to a strict due date."

In addition to effective instructional materials, students also appreciated the teaching materials stressing motivation and personalized assistance. One student stated, "I liked that the (course) provided very helpful hints and directions for the projects. The inclusion of the course checklist and the tutorials of websites that assisted in setting up a blog, website and step by step instructions for coding a webpage allowed for quicker completion of assignments."

Students also identified a number of typos, dead links, and a few content problems such as web tools that were no longer available. Because information and technology is constantly changing, these concerns were anticipated. However, these problems indicate the importance of ongoing maintenance of the course materials.

Students' positive attitudes towards the course were doubly confirmed by a Fall 2016 survey. This survey sampled 85 students who took the introductory course, but had not yet graduated. With a survey return rate of $27 \%$, the study confirmed that the course was effective in preparing students for the rigors of graduate school. One hundred percent of survey participants indicated that they felt the course helped "level the playing field" for incoming students, while $96 \%$ felt the course established the foundation for later graduate coursework and prepared them for the rigors of the graduate program. When asked about the most useful knowledge and skills acquired in the introductory course, students most frequently mentioned webpage development, creating citations, and building a blog. Most survey participants were able to list several courses where the skills were applied. Only two respondents indicated that the course was not useful. 
Department faculty members have found that students now enter their courses more prepared. Furthermore, the careful analysis, planning, and collaboration that went into developing this course has had far-reaching impact on the department as a whole. Because all of department faculty members were involved with both the needs assessment and formative evaluation stages, they became invested in the process. The possibility of adding "reflective practice" as a topic came up at a recent faculty meeting, and the ensuing conversations had ramifications from the entry-level course all the way through the program. This project has made collaborative discussions about curriculum development a regular part of departmental conversations.

\section{Conclusion}

Like other graduate students, those entering the graduate program in library science need information and technology skills. In addition to basic skills, entering graduate students also need other knowledge and skills related to librarianship to be successful in the graduate program. By applying a systematic approach to the design of instruction, the researcher was able to design an effective, efficient, and appealing course to meet the needs of incoming students.

The following suggestions and observations may be useful for graduate programs wishing to adapt this approach for their entry-level course:

- Follow the instructional design process precisely. Don't make assumptions about student needs or skip the formative evaluation to save time.

- When designing goals and objectives, think about the key knowledge and skills that will last throughout a student's graduate program rather than the current fads. While technology is constantly changing, most of the core skills remain the same. In other words, although students may be using cloud-based or app-based word processing tools, the basics of writing and editing have remained the same.

- $\quad$ The course will need ongoing supervision and maintenance. Caring instructors who constantly update and revise the course are essential. This means keeping up-to-date on changes in the profession and keeping an eye on what changes other institutions are making in their programs. The advantage, however, of creating small, focused tutorials is that they can be easily updated and expanded over time. The addition of new content would simply involve going back through the Dick and Carey model: developing goals, objectives, assessments, and matching instructional materials to focus on this newly suggested topic. Faculty members need time, resources, and the support of administration to develop high-quality online courses. This course took over a year and nearly five hundred hours to develop.

Although applying the Dick and Carey model to the design of an online course was time-intensive, the investment was worthwhile. Because learner needs were matched carefully to instruction, students were able to focus on acquiring new knowledge rather than wasting time revisiting areas where they already possessed skills. Student 
evaluations and feedback from faculty suggest that the redesign of the course was a success and that the Dick and Carey model is beneficial for those looking to reinvent courses at their own institutions.

\section{References}

American Association of School Librarians. (2007). Standards for the 21st Century Learner.

American Library Association. (2000). Information Literacy Competency Standards for Higher Education.

Association of College and Research Libraries Board (February 2, 2015). Framework for Information Literacy for Higher Education.

Bester, M., \& Scholtz, D. (2012). Mapping our way to coherence, alignment and responsiveness. South African Journal of Higher Education, 26(2), 282-299.

Booth, C. (2011). Reflective teaching, effective learning: Instructional literacy for library educators. Chicago, IL: ALA Editions.

Charles, L. H. (2015). Using an information literacy curriculum map as a means of communication and accountabilities for stakeholders in higher education. Journal of Information Literacy, 9(1), 47-61.

Chartered Institute of Library and Information Professionals. (2014). Information Literacy.

Daugman, E., McCall, L., \& McMahan, K. (2012). Designing and implementing an information literacy course in the humanities. Communications in Information Literacy, 5(2), 127-143.

Dick, W., Carey, L., \& Carey, J. O. (2009). The systematic design of instruction (7 ${ }^{\text {th }}$ ed.). Upper Saddle River, NJ: Pearson.

Farmer, L. S. J. (2011). Instructional design for librarians and information professional. New York: Neal-Schuman Publishers, Inc.

Gagné, R. M. (1985). Conditions of learning (4 ${ }^{\text {th }}$ ed.). New York: Holt, Rinehart, and Winston. 
Gagné, R. M., Wager, W. W., Golas, K. C., \& Keller, J M. (2004). Principles of instructional design. 5th edition. Boston, MA: Engage Learning.

Gunn, M., \& Miree, C. E. (2012). Business information literacy teaching at different academic levels: an exploration of skills and implications for instructional design. Journal of Information Literacy, 6(1), 18-34.

Hale, J.A. (2008). A guide to curriculum mapping: Planning, implementing, and sustaining the process. Thousand Oaks, CA: Corwin Press.

International Society for Technology in Education. (2015). ISTE Standards.

Ivanitskaya, L., DuFord, S., Craig, M., \& Casey, A. M. (2008). How does a preassessment of off-campus students' information literacy affect the effectiveness of library instruction? Journal of Library Administration, 48(3/4), 509-25.

Kaplowitz, J.R. (2012). Transforming information literacy instruction using learnercentered teaching. New York: Neal-Schuman Publishers.

Kaufman, R., \& English, F. W. (1979). Needs assessment: Concept and application. Englewood Cliffs, NJ: Educational Technology Publications.

Keller, J. M. (2010). Motivational design for learning and performance: The ARCS Model approach. New York: Springer.

Kumar, S., Ochoa, M., \& Edwards, M. (2012). Considering information literacy skills and needs: Designing library instruction for the online learner. Communications in Information Literacy, 6(1).

Lacy, M., \& Chen, H. (2013). Rethinking library instruction: using learning-outcome based design to teach online search strategies. Journal of Information Literacy, 7(2), 126-148.

Lowe, M., Booth, C., Tagge, N., \& Stone, S. (2014). Integrating an information literacy quiz into the learning management system. Communications in Information Literacy, 8(1).

Mager, R. F. (1997). Preparing instructional objectives ( $3^{\text {rd }}$ ed.). Atlanta, GA: Center for Effective Performance.

Merrill, M. D. (2013). First principles of instruction: Identifying and designing effective, efficient, and engaging instruction. San Francisco, CA: Pfeiffer.

Myers, D., \& Lamb, A. (1990). HyperCard authoring tool for presentations, tutorials \& information exploration. Orange, CA: Career Publishing. 
Radcliff, C. J., Jensen, M. L., Salem, J. A., Burhanna, K. J., \& Gedeon, J. A. (2007). A practical guide to information literacy assessment for academic librarians. Westport, CT: Libraries Unlimited.

Tyron J., Frigo, E., \& O'Kelly, M. (2010). Using teaching faculty focus groups to assess information literacy core competencies at university level. Journal of Information Literacy, 4(2), 62-77.

Uchiyama, K.P., \& Radin, J.L. (2009). Curriculum mapping in higher education: A vehicle for collaboration. Innovative Higher Education, 33(4), 271-280.

Weiner, S. A., Pelaez, N., Chang, K., \& Weiner, J. (2011). Biology and nursing students' perceptions of a web-based information literacy tutorial. Communications in Information Literacy, 5(2), 187-201. 


\section{Appendix}

List of 46 instructional tutorials designed for the introductory course

Part 1: Technology and Information Retrieval Basics

1.1 Course Management Systems

1.2 Technology Hardware and Software

1.3 Internet Use

1.4 Communication Technology

1.5 Information Access

1.6 Information Literacy \& the Library Profession

1.7 Information Retrieval and the Web

1.8 OPACs and Bibliographic Control

1.9 MARC

1.10 Metadata

1.11 Subject Analysis

1.12 Classification

1.13 Bibliographic Databases

1.14 Queries and Search Strategies

1.15 Bibliographic Citations

1.16 Resource Discovery

Part 2: Collection Management and Productivity Tools

2.1 Collection Management

2.2 Professional Information Management Tools

2.3 Electronic Resources

2.4 Technology Planning and Management

2.5 Technology Productivity \& Creativity Tools 


\section{$2.6 \quad$ Text Applications}

2.7 Graphic Applications

2.8 Spreadsheet Applications

2.9 Presentations

2.10 Audio Applications

2.11 Video Applications

Part 3: Social Media and Participatory Technology

3.1 Social Media and Participatory Technology

3.2 Social Media: Online Discussions

3.3 Social Media: Social Networks

3.4 Social Media: Blogs and Microblogs

3.5 Social Media: Collaborative Tech \& Wikis

3.6 Social Media: MUVEs

3.7 Interactive and Gaming Technology

Part 4: Advanced Technology, Ethics, and Professionalism

4.1 System Design, Info Arch, \& Advanced Tech

4.2 Web Design and Development

4.3 Web-based Technology: Widgets

4.4 Mobile Technology

4.5 Database Design and Management

4.6 Library Ethics \& Professionalism

4.7 Access

4.8 Intellectual Freedom

4.9 Privacy and Confidentiality

4.10 Intellectual Property and Copyright 
Partnership: The Canadian Journal of Library and Information Practice and Research, vol. 11, no. 2 (2016)

\subsection{Digital Security}

\subsection{Human-Computer Interaction}

